\title{
Concerns about Soy Cultivation: What is Known and What is not Known
}

Jargin $\mathrm{SV}^{*}$

Peoples' Friendship University of Russia

*Corresponding author: Jargin SV, Peoples’ Friendship University of Russia, Moscow, Russia, E-mail: sjargin@ mail.ru

\author{
Citation: Jargin SV (2014) Concerns about Soy Cultivation: What is Known and What is not Known. J Nutr
} Health Sci 1(3): 310. doi: 10.15744/2393-9060.1.310

Received Date: October 27, 2014 Accepted Date: November 05, 2014 Published Date: November 07, 2014

\begin{abstract}
There is a discrepancy in how phytoestrogens and soy products are viewed in science and medicine. Among edible plants, phytoestrogens are most abundant in soy, and are structurally and functionally analogous to estrogens, with their biological action mediated by estrogen receptors. Soy products are widely used in infant food and other foodstuffs; and, at the same time, phytoestrogens have been applied for compensation of hormone deficiency in menopause. Furthermore, soy is applied as livestock fodder, and residual phytoestrogens and their active metabolites can remain in meats. There are only few reports on modified gender-related behavior or feminization in humans as a result of soy consumption. In animals, the intake of phytoestrogens was reported to impact fertility, sexual development and behavior. Feminizing effects in humans can be subtle and identifiable only statistically in large populations, and may be of particular significance for children and adolescents. This matter should be clarified by independent research, which may affect the future of soy cultivation.
\end{abstract}

Keywords: Phytoestrogens; Isoflavones; Soy; Nutrition

There is abundant literature suggesting medical use for phytoestrogen-containing products. There is also published evidence suggesting potentially negative consequences of phytoestrogens use for humans. Substantiation of both concepts appears questionable. Meanwhile, soy products are used liberally in the food also for infants and children. The concept discussed here is that it is not consistent to support soy use for estrogenic effects without concern for its impact on routine use as a foodstuff and livestock fodder. It is important for thorough independent studies to be done to answer these questions. Phytoestrogens are substances of plant origin that are structurally and functionally similar to estrogens. Among them, isoflavones and coumestans are the most extensively studied groups. Isoflavones are present in different edible plants, but are most abundant in soy [13]. Consumption of soy products has been associated with favorable health effects, but potentially adverse effects are underacknowledged [4]. Phytoestrogens are advertised as a natural alternative to estrogens for hormone replacement therapy during menopause [1]. Preclinical trials have demonstrated both genomic and non-genomic action of phytoestrogens including selective but weak binding to the estrogen receptors [5]. Some epidemiological studies suggest that dietary intake of phytoestrogens may contribute to the decreased incidence of postmenopausal cardiovascular disease [6] and that phytoestrogens are significantly more effective than placebo in reducing the frequency of hot flashes [7]. Evidence in support of clinically relevant biological effects has been generally rated as insufficient or absent [5,8-14]. A recent review concluded that in spite of increasing preclinical and clinical studies over the past decade, "appealing evidence is still lacking to support the overall positive risk-benefit profile of phytoestrogens" [15]. Then as now, the conventional menopausal hormone replacement therapy remains the only treatment that has consistently had a greater effect than placebo in controlled trials [16]. As evaluation of earlier works on enrichment the diet with soy products has failed to confirm favorable effects related to the cardiovascular system [17], doubts concerning phytoestrogens have recently increased. There is little evidence to support the hypothesis that phytoestrogens protect against menopausal osteoporosis, with published studies having no controls for confounding factors, the observations generally being of short duration $[18,19]$. In regard to osteoporosis, the latest review concluded that "evidence points to a lack of a protective role of soy isoflavones in the prevention of postmenopausal bone loss" [20], although in vitro and animal studies show some positive effect of isoflavones on bone which has not been clearly confirmed by long-term human trials [21]. There might be genetic differences in this regard, as equol producers seem to present a more positive response to isoflavone intervention [21]. The use of phytoestrogens as an alternative for hormone replacement therapy is not advocated due to insufficient information on safety [22], and reports of adverse effects and interactions with drugs [23]. Moreover, soy is known as allergenic food [2,24], and soybeanbased oil emulsions have been identified as one of the major causes of cholestasis related to pediatric parenteral nutrition [25].

Given that the biological action of estrogens is mediated by receptors, it should be questioned, why must the incidental plant analogues be used for replacement therapy instead of the natural or synthetic hormones that are more complimentary to the receptors? Furthermore, commercial preparations often contain a mixture of ingredients of unknown concentrations [26]. It should also be remarked that mixed preparations containing both phytoestrogens and estrogens, if phytoestrogens indeed bind selectively to the estrogen receptors [5], they might inhibit the action of the estrogens by competing with them for the binding sites, which would possibly increase the required dose. 
Phytoestrogens are used to compensate for hormone deficiency in the menopause, but their hormonal potential does not prevent the broad use of soy in infant food, other foodstuffs and pediatric parenteral nutrition [25]. Given the extensive use of soy for animal fodder, residual phytoestrogens and their active metabolites, in the first place equol, produced by intestinal bacteria in cattle and domestic fowl $[27,28]$, can remain in meat and influence the hormonal balance of consumers. Apart from few reports e.g. on the changes of the gender-related behavior in girls [29] or gynaecomastia in a man [30] after the intake of soy products, no data on the modification of gender-related characteristics or feminization in humans in consequence of soy consumption have been found, although phytoestrogens were reported to exert anti-androgenic effects in patients with castration-resistant prostate cancer [31]. In animals, the intake of phytoestrogens was reported to impact fertility and the morphogenesis of ovaries, e.g. "clover disease" in sheep [15,32], be associated with derangements of sexual development and behavior in male rats [33,34], mammary gland hyperplasia in male rats [35] etc. Feminizing in humans can be subtle and identifiable only statistically in large populations. It has been argued that phytoestrogens are selective receptor modulators thus acting differently from the natural estrogens, not necessarily feminizing [36]. Yet the question remains whether such modulations are desirable for consumers of soy products, including infants receiving soy nutrition. The words "modulation" and "regulation" are sometimes used to make impression that botanicals have a priori beneficial effects, although this is often groundless. "Regulation" for the benefit of the human organism presupposes consciousness and will. For example, when it is stated that "available knowledge suggests that phytoestrogens can affect a number of physiological and pathological processes related to reproduction, bone remodeling, skin, cardiovascular, nervous, immune systems and metabolism" [37] it is still not a matter-of-course that "due to these effects, phytoestrogens and phytoestrogen-containing diet can be useful for the prevention and treatment of menopausal symptoms, skin aging, osteoporosis, cancer, cardiovascular, neurodegenerative, immune and metabolic diseases" [37]. Clinically relevant effects should be proven according to the principles of evidence-based medicine. The supposition that botanicals are "natural" for the human organism can be misleading - it is well known that many substances of plant origin are toxic. The marketing of botanicals with unproven effects in the guise of evidence-based medications has been commented upon previously [38]. In this context, it is sometimes difficult to distinguish between reliable and unreliable publications.

For example, a supposed anti-atherogenic effect of phytoestrogens-containing preparations of plant origin was reported on the basis of experiments with cell cultures, where the ability of serum to induce the accumulation of lipids in cultured macrophages or smooth muscle cells was interpreted as an indicator of serum atherogenicity [39-41]. Anti-atherogenic actions of different drugs and substances of plant origin were measured in the cell cultures [42-45]: if an agent induced lipid accumulation by the cultured cells it was deemed atherogenic and vice versa. As discussed previously however [38], if a pharmacological agent lowers the uptake of lipids by cells in a culture, it should be expected to increase the blood cholesterol level in vivo. So, in familial hypercholesterolemia, a genetic abnormality of lipoprotein receptors impeding cholesterol uptake by cells from blood results in accelerated atherosclerosis [46,47]. Blood levels of the most abundant cholesterol-carrying lipoproteins i.e. the low density lipoproteins (LDL) largely depend on the LDL-receptors. Under the usual circumstances of tissue culture, most cells rely on LDL receptors as a source of cholesterol [48]. Lipoprotein receptors both of classical and scavenger types have been found on the macrophages and smooth muscle cells [49-52]. It appears probable that the role of the scavenger receptors in the uptake from blood of modified (oxidized) LDL is analogous to that of the classical receptors with regard to the native LDL at least under certain pathological conditions. So, the basal expression of the scavenger receptors LOX-1 is relatively low; but it can be induced by pro-inflammatory cytokines and other pathological stimuli relevant to atherosclerosis, including the oxidized LDL $[52,53]$. Considering the above, it can be reasonably assumed that if a pharmacological agent impedes cholesterol uptake by cells in a culture, inhibiting the receptor-mediated mechanisms or otherwise, it should be awaited to elevate the blood cholesterol level in vivo. Moreover, the endothelial dysfunction, one of the central events in the atherogenesis, is not reproduced in the cell monocultures. Nonetheless the cell cultures have been used in Russia since about 25 years $[42,43,45,54]$ for testing of supposedly anti-atherogenic drugs and dietary supplements including phytoestrogens in support for their official registration.

\section{Conclusion}

There is a discrepancy in how phytoestrogens and soy products are viewed in science and medicine. Phytoestrogens are present in different edible plants, though are most abundant in soy. They are used to compensate for estrogen deficiency in menopause, but the estrogenic potential does not prevent their extensive use in infant food, other foodstuffs and pediatric parenteral nutrition. Feminizing effect of phytoestrogens and soy products may be subtle, detectable only statistically in large populations, and may be of particular importance for children and adolescents. This matter should be clarified by independent research, despite its potential implications for future soy cultivation. In view of the title of this paper, the following concerns should be stressed in conclusion: (1) the concern for soy use in children and adolescents, given possible estrogenic effects; (2) the concern for phytoestrogens and soy use as ingredients of drugs and dietary supplements for its estrogenic action whereas the literature does not confirm consistent therapeutic effects; (3) the concern to acknowledge that both effect and assumption of no effect cannot be ignored without more profound independent investigation when there is an effect and when there is not.

\section{Acknowledgment}

The author is sincerely grateful to all colleagues who participated in discussion and improvement of this paper, and to Dr. Bronwyn Ellis for proofreading the final version of the text. 


\section{References}

1. Patisaul HB, Jefferson W (2010) The pros and cons of phytoestrogens. Front Neuroendocrinol 31: 400-19.

2. Barnes S (2010) The biochemistry, chemistry and physiology of the isoflavones in soybeans and their food products. Lymphat Res Biol 8: 89-98.

3. Nestel PJ, Pomeroy S, Kay S, Behrsing J, Cameron JD, et al. (1999) Isoflavones from red clover improve systemic arterial compliance but not plasma lipids in menopausal women. J Clin Endocrinol Metab 84: 895-8.

4. Cederroth CR, Zimmermann C, Nef S (2012) Soy, phytoestrogens and their impact on reproductive health. Mol Cell Endocrinol 355: 192-200.

5. Baber R (2010) Phytoestrogens and post reproductive health. Maturitas 66: 344-9.

6. Gencel VB, Benjamin MM, Bahou SN, Khalil RA (2012) Vascular effects of phytoestrogens and alternative menopausal hormone therapy in cardiovascular disease. Mini Rev Med Chem 12: 149-74.

7. Taku K, Melby MK, Kronenberg F, Kurzer MS, Messina M (2012) Extracted or synthesized soybean isoflavones reduce menopausal hot flash frequency and severity: systematic review and meta-analysis of randomized controlled trials. Menopause 19: 776-90.

8. Gold EB, Leung K, Crawford SL, Huang MH, Waetjen LE, et al. (2013) Phytoestrogen and fiber intakes in relation to incident vasomotor symptoms: results from the Study of Women's Health Across the Nation. Menopause 20: 305-14.

9. Lethaby A, Marjoribanks J, Kronenberg F, Roberts H, Eden J, et al. (2013) Phytoestrogens for menopausal vasomotor symptoms. Cochrane Database Syst Rev 12: CD001395.

10. Krebs EE, Ensrud KE, MacDonald R, Wilt TJ (2004) Phytoestrogens for treatment of menopausal symptoms: a systematic review. Obstet Gynecol 104: 824-36. 11. Cheema D, Coomarasamy A, El-Toukhy T (2007) Non-hormonal therapy of post-menopausal vasomotor symptoms: a structured evidence-based review. Arch Gynecol Obstet 276: 463-9.

12. Al-Azzawi F, Wahab M (2010) Effectiveness of phytoestrogens in climacteric medicine. Ann N Y Acad Sci 1205: 262-7.

13. Villaseca P (2012) Non-estrogen conventional and phytochemical treatments for vasomotor symptoms: what needs to be known for practice. Climacteric 15 : $115-24$.

14. Speroff L (2005) Alternative therapies for postmenopausal women. Int J Fertil Womens Med 50: 101-14.

15. Poluzzi E, Piccinni C, Raschi E, Rampa A, Recanatini M, et al. (2014) Phytoestrogens in postmenopause: the state of the art from a chemical, pharmacological and regulatory perspective. Curr Med Chem 21: 417-36.

16. de Villiers TJ, Bagratee JS, Dalmeyer JP, Davey MR, Davis CP, et al. (2007) South African Menopause Society Council revised consensus position statement on menopausal hormone therapy. S Afr Med J 97: 354-7.

17. Sirtori CR, Arnoldi A, Johnson SK (2005) Phytoestrogens: end of a tale? Ann Med 37: 423-38.

18. Davis SR (2001) Phytoestrogen therapy for menopausal symptoms? BMJ 323: 354-5.

19. Coxam V (2008) Phyto-oestrogens and bone health. Proc Nutr Soc 67: 184-95.

20. Lagari VS, Levis S (2013) Phytoestrogens in the prevention of postmenopausal bone loss. J Clin Densitom 16: 445-9.

21. Castelo-Branco C, Soveral I (2013) Phytoestrogens and bone health at different reproductive stages. Gynecol Endocrinol 29: 735-43.

22. This P, de Cremoux P, Leclercq G, Jacquot Y (2011) A critical view of the effects of phytoestrogens on hot flashes and breast cancer risk. Maturitas 70: 222-6.

23. Haimov-Kochman R, Brzezinski A, Hochner-Celnikier D (2008) Herbal remedies for menopausal symptoms: are we cautious enough? Eur J Contracept Reprod Health Care 13: 133-7.

24. Wilson S, Blaschek K, de Mejia E (2005) Allergenic proteins in soybean: processing and reduction of P34 allergenicity. Nutr Rev 63: 47-58.

25. Saayman BD (2011) The use of alternative lipid emulsions in paediatric and neonatal parenteral nutrition. S Afr J Clin Nutr 24: S32-4.

26. Leclercq G, de Cremoux P, This P, Jacquot Y (2011) Lack of sufficient information on the specificity and selectivity of commercial phytoestrogens preparations for therapeutic purposes. Maturitas 68: 56-64.

27. Usui T (2006) Pharmaceutical prospects of phytoestrogens. Endocr J 53: 7-20.

28. Setchell KD, Clerici C (2010) Equol: history, chemistry, and formation. J Nutr 140: 1355-62S.

29. Adgent MA, Daniels JL, Edwards LJ, Siega-Riz AM, Rogan WJ (2011) Early-life soy exposure and gender-role play behavior in children. Environ Health Perspect 119: 1811-6.

30. Martinez J, Lewi JE (2008) An unusual case of gynecomastia associated with soy product consumption. Endocr Pract 14: 415-8.

31. Thelen P, Wuttke W, Seidlová-Wuttke D (2014) Phytoestrogens selective for the estrogen receptor beta exert anti-androgenic effects in castration resistant prostate cancer. J Steroid Biochem Mol Biol 139: 290-3.

32. Jefferson WN, Williams CJ (2011) Circulating levels of genistein in the neonate, apart from dose and route, predict future adverse female reproductive outcomes. Reprod Toxicol 31: 272-9.

33. Whitten PL, Lewis C, Russell E, Naftolin F (1995) Potential adverse effects of phytoestrogens. J Nutr 125: 771-6S.

34. Seliukova NIu, Karpenko NO, Korenieva IeM, Somova OV, Smolienko NP, et al. (2014) The impact of male phytoestrogenization on the somato-sexual development and fertility of the offsprings in rats. Fiziol Zh 60: 82-7.

35. Latendresse JR, Bucci TJ, Olson G, Mellick P, Weis CC, et al. (2009) Genistein and ethinyl estradiol dietary exposure in multigenerational and chronic studies induce similar proliferative lesions in mammary gland of male Sprague-Dawley rats. Reprod Toxicol 28: 342-53.

36. Messina M, Melby MK, Kronenberg F, Kurzer MS, Taku K (2013) Letter to the editor. Menopause 20: 359-61.

37. Sirotkin AV, Harrath AH (2014) Phytoestrogens and their effects. Eur J Pharmacol 741: 230-6.

38. Jargin SV, Wilson DW (2014) Some pitfalls in testing antiatherogenic agents in cell cultures. World Heart J 6 149-55.

39. Nikitina NA, Sobenin IA, Myasoedova VA, Korennaya VV, Mel'nichenko AA, et al. (2006) Antiatherogenic effect of grape flavonoids in an ex vivo model. Bull Exp Biol Med 141: 712-5.

40. Orekhov AN, Sobenin IA, Korneev NV, Kirichenko TV, Myasoedova VA, et al. (2013) Anti-atherosclerotic therapy based on botanicals. Recent Pat Cardiovasc Drug Discov 8: 56-66.

41. Korennaya VV, Myasoedova VA, Nikitina NA, Sobenin IA, Orekhov AN (2006) Bioflavonoid-rich botanicals reduce blood serum atherogenicity in perimenopausal women. Abstracts of the XIV International Symposium on Atherosclerosis (ISA), 18-22 June 2006, Rome, Italy. Atheroscler Suppl 7: 444.

42. Ryong LH, Tertov VV, Vasilev AV, Tutel'yan VA, Orekhov AN (1989) Antiatherogenic and antiatherosclerotic effects of mushroom extracts revealed in human aortic intima cell culture. Drug Dev Res 17:109-17.

43. Orekhov AN, Baldenkov GN, Tertov VV, Ryong LH, Kozlov SG, et al. (1988) Cardiovascular drugs and atherosclerosis: Effects of calcium antagonists, betablockers, and nitrates on atherosclerotic characteristics of human aortic cells. J Cardiovasc Pharmacol 12 Suppl 6: S66-8. 
44. Orekhov AN, Melnichenko AA, Sobenin IA (2014) Approach to reduction of blood atherogenicity. Oxid Med Cell Longev 2014: 738679.

45. Orekhov AN, Pivovarova EM, Sobenin IA, Yakushkin VV, Tertov VV (1992) Use of cell culture for optimisation of direct antiatherogenic therapy with verapamil. Drugs 1: 105-10.

46. Marais AD (2004) Familial hypercholesterolaemia. Clin Biochem Rev 25: 49-68.

47. Goldstein JL, Brown MS (2009) The LDL receptor. Arterioscler Thromb Vasc Biol 29: 431-8.

48. Goldstein JL, Brown MS (1984) Progress in understanding the LDL receptor and HMG-CoA reductase, two membrane proteins that regulate the plasma cholesterol. J Lipid Res 25: 1450-61.

49. Ricciarelli R, Zingg JM, Azzi A (2000) Vitamin E reduces the uptake of oxidized LDL by inhibiting CD36 scavenger receptor expression in cultured aortic smooth muscle cells. Circulation 102: 82-7.

50. Llorente-Cortés V, Badimon L (2005) LDL receptor-related protein and the vascular wall: implications for atherothrombosis. Arterioscler Thromb Vasc Biol 25: 497-504.

51. Gong Q, Pitas RE (1995) Synergistic effects of growth factors on the regulation of smooth muscle cell scavenger receptor activity. J Biol Chem 270: $21672-8$.

52. Pirillo A, Norata GD, Catapano AL (2013) LOX-1, OxLDL, and atherosclerosis. Mediators Inflamm 2013: 152786.

53. Xu S, Ogura S, Chen J, Little PJ, Moss J, Liu P (2013) LOX-1 in atherosclerosis: biological functions and pharmacological modifiers. Cell Mol. Life Sci 70: 2859-72.

54. Chazov EI, Tertov VV, Orekhov AN, Lyakishev AA, Perova NV, et al. (1986) Atherogenicity of blood serum from patients with coronary heart disease. Lancet 2: $595-8$.

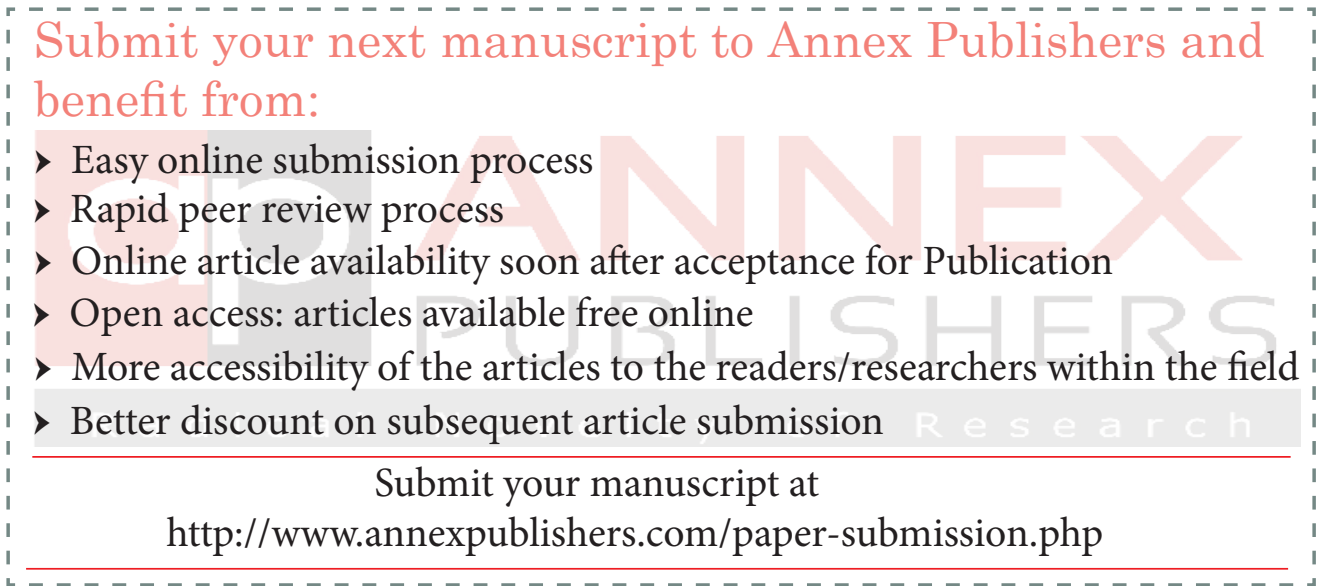

